\title{
ANALISIS KADAR $\beta$-KAROTEN BUAH PISANG RAJA (MUSA PARADISIACAL L) DAN PISANG KEPOK (MUSA PARADISLACA FORMA TYPICA) DENGAN METODE SPEKTROFOTOMETRI UV-Vis
}

\author{
Analysis of $\beta$-Karoten Level of Raja Banana (Musa Paradisiacal L.) and \\ Kepok Banana (Musa Paradisiaca Forma Typical) with \\ UV-V is Spectrophotometry Method
}

\section{*Zarnila, Mery Napitupulu, dan Minarni Rama Jura}

Pendidikan Kimia/FKIP - Universitas Tadulako, Palu - Indonesia 94118

Received 23 August 2018, Revised 06 October 2018, Accepted 11 November 2018

\begin{abstract}
Banana fruit is a fruit that contains many nutrients. One of that is $\beta$-carotene, which is a provitamin that plays an important role for the formation of vitamin $A$. This study aimed to determine the levels of $\beta$-carotene in raja and kepok bananas. This research used qualitative and quantitative method, which is the qualitative method using TLC while the quantitative method using UV-VIS spectrophotometry. The TLC results obtained that Rf $\beta$-carotene comparison was $0.97 \mathrm{~cm}, R f$ of banana raja extract was $0.96 \mathrm{~cm}$ and banana kepok extract was $0.97 \mathrm{~cm}$. Based on the UV-Vis spectrofotometry result, $\beta$-carotene content of raja banana fruit was $0.222 \mathrm{mg} / 100 \mathrm{grams}$ while the kepok banana fruit was $0.261 \mathrm{mg} / 100$ grams, therefore the highest level was banana kepok.
\end{abstract}

\section{Pendahuluan}

Buah pisang selain dapat memiliki nilai ekonomis yang tinggi, juga mengandung nilai gizi yang tinggi sebagai sumber karbohidrat, vitamin, dan mineral. Kandungan karbohidratnya terutama berupa zat tepung atau pati dan macam-macam gula. Kandungan gula dalam pisang terdiri atas senyawasenyawa seperti fruktosa, glukosa dan sukrosa. Ketiga jenis gula tersebut sangat baik dicerna oleh tubuh manusia disegala usia (Sarjana, 1997). Buah pisang mudah rusak Salah satu penyebab rusaknya buah pisang akibat adanya gas etilen yang dihasilkan buah pisang itu sendiri. Semakin tinggi kadar gas etilen semakin cepat pula kematangan buah pisang (Sholihati, dkk., 2015).

Satu jenis pisang yang banyak dikonsumsi oleh masyarakat Indonesia adalah pisang kepok dan pisang raja. Pisang kepok memiliki kulit yang sangat tebal dengan warna kuning kehijauan dan kadang bernoda cokelat, serta daging buahnya manis. Pisang kepok memiliki warna daging buah putih dan kuning (Prabawati \& Setyabudi, 2008). Pisang kepok kuning rasa buahnya lebih enak dibandingkan kepok putih sehingga lebih disukai dan harganya lebih mahal. Hal ini dikarenakan pisang kepok kuning dengan tingkat ketuaannya yang cukup (cukup tua tetapi belum masak) merupakan tingkat kadar pati maksimum (Prabawati \& Setyabudi, 2008).

Pisang raja (Musa paradisiacal L.) merupakan salah satu kultivar pisang yang terkenal baik di kita maupun di desa. Selain untuk buah yang dimakan langsung secara segar, pisang raja juga banyak digunakan untuk bahan utama berbagai makanan olahan pisang misalnya pisang goring, kripik pisang

${ }^{*}$ Correspondence:

Zarnila A. P.

Program Studi Pendidikan Kimia, Fakultas Keguruan dan Ilmu Pendidikan, Universitas Tadulako

e-mail: puangolozarnila@gmail.com

Published by Universitas Tadulako 2018 dan sale pisang. Pisang raja juga sering disebut pisang meja karena sering diletakkan di atas meja sebagai buah pencuci mulut yang dikonsumsi dalam bentuk buah segar setelah masak di pohon ataupun melalui proses pemeraman (Utami, dkk., 1999).

Buah pisang mengandung karotenoid. Karotenoid adalah suatu pigmen alami berupa zat warna kuning sampai merah yang mempunyai struktur alifatik atau siklik. Berdasarkan fungsinya karotenoid dibagi atas dua golongan yaitu berupa nutrisi aktif, seperti $\beta$-karoten dan nutrisi non aktif seperti fukoxantin dan violaxantin (Priata, 1996). Kandungan $\beta$-karoten bermanfaat sebagai antioksidan pencegah kanker, beragam penyakit kardiovaskuler, dan katarak (Badarinath, dkk., 2010).

Berdasarkan unsur penyusunannya, penggolongan karotenoid menjadi 2 yaitu golongan yang tersusun oleh atom-atom $\mathrm{C}$ dan $\mathrm{H}$, seperti $\alpha, \beta$, $\gamma$ karetonoid dan golongan oksikaroten atau xantofil yang tersusun oleh unsur-unsur $\mathrm{C}, \mathrm{H}$ dan $\mathrm{OH}$ (Hastinah, 1996). $\beta$-karoten merupakan pigmen tumbuhan, dan merupakan provitamin A yang paling penting bagi manusia (Almatsier, 2004).

Hasil penelitian Susila (2010) menunjukan bahwa sayuran dan buah-buahan yang berwarna hijau atau kuning banyak mengandung karoten yaitu $\alpha, \beta$ dan $\gamma$ karoten. Buah-buahan dan sayuran banyak dilakukan penelitian salah satunya buah pare (Tadjuddin, dkk., 2012) dan ubi jalar ungu (Fitri dkk., 2015). Kemudian buah naga merah dan naga putih (Dwi dkk., 2015).

Artikel ini mengurai analisis $\beta$-karoten yang terkandung dalam pisang raja dan pisang kapok menggunakan metode spetrofotometri.

\section{Metode}

\section{Alat dan bahan}

Alat-alat yang digunakan pada penelitian ini meliputi Spektrofotometri UV-Vis, aluminium foil, plat kromatografi lapis tipis, corong pisah, kertas 
saring, labu ukur, gelas kimia, spatula, alat centrifuge, batang pengaduk, champer kromatografi lapis tipis, gelas ukur, plat kromatografi lapis tipis dan sinar UV. Bahan yang digunakan adalah padatan $\beta$-karoten p.a (Merck), aquades, aseton p.a (Merck), benzen p.a (Merck), Petroleum Eter p.a (Merck), butil hidroksi toluen (PT. Brataco), natrium klorida p.a (Merck), natrium sulfat anhidrat p.a (Merck), daging buah pisang kepok dan daging buah pisang raja.

\section{Persiapan sampel}

Sampel daging buah pisang raja dan daging buah pisang kapok di peroleh di desa Pantoloan Kecamatan Tawaeli. Daging buah pisang dibersihkan lalu dipotong kecil dan dihaluskan.

\section{Tahap ekstraksi}

0,019 gram BHT ditimbang dan ditambahkan petroleum eter dan aseton perbandingan 1:4. Masingmasing sampel daging buah pisang yang halus ditimbang sebanyak 50 gram. Kemudian ditambahkan ke dalam petroleum eter : aseton berisi BHT $100 \mathrm{~mL}$. Proses ekstraksi menggunakan alat centrifuge lalu diambil filtratnya. Ampas dicuci sebanyak $3 \mathrm{x}$ dengan perlakuan yang sama. Campurkan filtrat dengan volume aseton $250 \mathrm{~mL}$ masukkan dalam corong pisah tambahkan aquades $250 \mathrm{~mL}$ secara perlahan di dinding corong pisah dan $2 \mathrm{~mL} \mathrm{NaCl}$ jenuh, kocok selama \pm 30 menit lalu didiamkan hingga terbentuk dua fase yaitu fase petroleum eter dan air. Fase air dikeluarkan dari corong pisah secara perlahan. Ditambahkan aquades $200 \mathrm{~mL}$. ulangi sebanyak 3x pengulangan. Keluarkan fase petroleum eter dari dalam corong pisah ke dalam labu ukur $25 \mathrm{~mL}$ dengan cara saring di atas kertas saring letakkan natrium sulfat anhidrat secukupnya.

\section{Analisis kualitatif}

Menyiapkan chamber dengan pelarut pengelusi yaitu petroleum eter:benzen $(9: 1)$ dan plat KLT. Larutan $\beta$-karoten murni sebagai pembanding. Totolkan sampel dan pembanding bersama-sama pada lempeng KLT dengan jarak $1 \mathrm{~cm}$ dari tepi bawah lempeng KLT, beri tanda pada jarak rambat. Setelah kering lempeng KLT masukkan ke dalam chamber yang berisi cairan pengelusi. Tutup bejana dan biarkan sitem hingga fase gerak merambat sampai batas jarak rambat. Keluarkan lempeng dan keringkan dan amati bercak dengan lampu UV. Ukur dan catat tiap-tiap bercak dari titik penotolan. Tentukan Retension factor (Rf).

$$
\mathrm{Rf}=\frac{\text { jarak yang ditempuh substansi }}{\text { jarak yang ditempuh pelarut }}
$$

\section{Tahap Kuantitatif}

\section{Pembuatan larutan induk $\beta$-karoten 50 ppm}

0,001 gram $\beta$-karoten murni ditimbang kemudian dilarutkan $15 \mathrm{~mL}$ petroleum eter dalam labu ukur $25 \mathrm{ml}$ lalu dicukupkan volumenya $25 \mathrm{ml}$, diperoleh larutan dengan konsentrasi 50 ppm.

\section{Penentuan kurva kalibrasi}

Pembuatan larutan seri standar $\beta$-karoten konsentrasi 5, 10, 15, 20, dan 25 ppm. Larutan induk $\beta$-karoten murni $50 \mathrm{ppm}$ sebanyak $1,2,3,4$ dan $5 \mathrm{~mL}$ dipipet dan dicukupkan volume sebanyak $10 \mathrm{~mL}$ dengan petroleum eter, Diukur absorbansi dengan Spektrofotometri UV-Vis pada panjang gelombang $450 \mathrm{~nm}$.

Pada penentuan kadar $\beta$-karoten, ekstrak yang diperoleh dimasukkan ke dalam labu ukur $25 \mathrm{~mL}$, dilarutkan dengan petroleum eter hingga homogen dan diencerkan hingga tanda batas. Untuk blanko digunakan petroleum eter, diukur absorbannya dengan Spektrofotometri UV-Vis pada panjang gelombang maksimum. Kadar $\beta$-karoten pada sampel ditentukan berdasarkan persamaan regresi linear. Analisis kadar $\beta$-karoten ditentukan berdasarkan persamaan regresi linear: $y=b x+a$, dimana $y$ adalah serapan dan $\mathrm{x}$ adalah konsentrasi dalam $\mathrm{mg} / \mathrm{gram}$.

\section{Hasil dan Pembahasan}

Peneltian ini dilakukan untuk meganalisis kadar $\beta$-karoten buah daging pisang raja dan daging buah pisang kepok. Sampel yang digunakan yaitu daging buah pisang raja dan pisang kepok yang diperoleh dari desa Pantoloan. Dalam sampel daging buah pisang dianalisis kadar $\beta$-karoten menggunakan spektrofotometri $\mathrm{Uv}_{\mathrm{V}-\mathrm{V} \text { is. }}$

Analisis kadar $\beta$-karoten dilakukan yaitu sampel dihaluskan dan diekstrak. Ekstraksi adalah proses pemisahan suatu zat berdasarkan perbedaan kelarutannya terhadap dua cairan yang tidak saling larut (Mailoa, dkk., 2014). Ekstraksi memiliki kelebihan yaitu agar proses analisis lebih mudah dan cepat. Ekstraksi bertujuan untuk memindahkan senyawa $\beta$-karoten yang terkandung di dalam daging buah pisang ke dalam larutan petroleum eter. Sampel yang ditambahkan padatan BHT sebagai antioksidan karena $\beta$-karoten mudah teroksidasi dan pelarut yang digunakan yaitu petroleum eter dan aseton dimana petroleum eter bersifat hidrofobik (larut lemak) sehingga mudah menarik senyawa karotenoid sedangkan aseton bersifat hidrofilik (suka air) maka mudah menarik seluruh senyawa organik yang terkandung dalam daging buah pisang. Menggunakan alat centrifuge untuk ekstraksi dengan tujuan agar sampel cepat terpisah dari kelarutan dua cairan yang tidak saling larut. Proses ekstraksi dilakukan sebanyak 3x agar sampel benar-benar tersari dengan sempurna . Filtrat masing-masing hasil ekstraksi ditambahkan menggunakan aseton dan aquades karena sifatnya yang sama sehingga lebih mudah lagi untuk menarik seluruh senyawa organik yang terkandung dalam daging buah pisang. Selanjutnya penambahan $2 \mathrm{~mL}$ $\mathrm{NaCl}$ jenuh untuk menghindari terjadinya emulsi. Emulsi dapat dipecahkan dengan adanya elektrolit dan menambah tingkat ionisasi dari air menjadi lebih polar maka kemampuan pemisahan air dengan petroleum eter akan bertambah dalam pemisahan fase. Lalu dilakukan pengocokkan selama \pm 30 menit terbentuk dua fase yaitu fase air dan fase petroleum 
eter. Pengocokan berfungsi untuk memaksimalkan penarikan $\beta$-karoten. Dilakukan proses penyaringan fase air dikeluarkan dan fase petroleum eter ditambahkan menggunakan aquades dilakukan sebanyak 3x. Hal ini dikarenakan untuk menghilangkan sisa dari aseton yang menempel. Selanjutnya petroleum eter disaring dengan kertas saring yang dilapisi natrium sulfat anhidrat untuk menghilangkan sisa air. Setelah itu ditambahkan volumenya menggunakan petroleum eter sebanyak 25 $\mathrm{mL}$.

Uji kualitatif menggunakan Kromatografi lapis tipis. KLT digunakan dalam penentuan $\beta$ karoten karena memiliki sensitivitas tinggi (terbukti dengan hasil pengukuran yang valid) dan relative lebih murah (Parwata, dkk., 2010). Menggunakan kromatografi lapis tipis dilihat dari nilai Rf. Nilai $\mathrm{Rf}$ adalah perbandingan jarak yang ditempuh solut dengan jarak yang ditempuh dengan fase gerak.

Tabel 1. Hasil analisis kualitatif menggunakan KLT

\begin{tabular}{|c|c|c|c|}
\hline $\begin{array}{l}\text { Penampaka } \\
\text { n Noda }\end{array}$ & $\begin{array}{l}\beta \text {-karoten } \\
\text { murni }\end{array}$ & $\begin{array}{l}\text { Daging buah } \\
\text { pisang raja }\end{array}$ & $\begin{array}{l}\text { Daging buah } \\
\text { pisang kepok }\end{array}$ \\
\hline Sinar UV & $\begin{array}{l}\text { Bercak } \\
\text { warna } \\
\text { kuning }\end{array}$ & $\begin{array}{l}\text { Bercak warna } \\
\text { kuning }\end{array}$ & $\begin{array}{l}\text { Bercak } \\
\text { kuning }\end{array}$ \\
\hline $\begin{array}{l}\text { Nilai } \quad \text { Rf } \\
(\mathrm{cm})\end{array}$ & 0,97 & 0,96 & $0,97 \mathrm{c}$ \\
\hline
\end{tabular}

Hasil penelitian menunjukkan adanya bercak berwarna kuning dan mempunyai nilai Rf yang sama dengan senyawa pembandingnya. Uji kualitatif dilakukan beberapa kali agar bercak yang dihasilkan benar-benar $\beta$-karoten bukan kandungan vitamin yang lain salah satunya vitamin yang memiliki warna yang sama seperti vitamin $C$ tetapi dilihat dari masing-masing larutan yang digunakan dimana vitamin $C$ tidak dapat larut dalam larutan pentroleum eter, kloroform dan larutan benzen sedangkan dalam penelitian ini yaitu analisis $\beta$-karoten banyak menggunakan petroleum eter dan benzen kemudian dilihat dari kelarutan vitamin $\mathrm{C}$ larut dalam air sedangkan. $\beta$-karoten larut dalam lemak.

Selanjutnya uji kuantitatif menggunakan Spektrofotometri Uv-Vis. Prinsip kerja spektrofotometri yaitu cahaya dipancarkan dan diteruskan serta diserap oleh suatu larutan yang diperiksa dalam kuvet (Triyati E., 1985).

Pengukuran kadar $\beta$-karoten ini bertujuan untuk mengetahui banyaknya kandungan $\beta$-karoten masing-masing sampel. Kurva standar dibuat dengan melarutkan $\beta$-karoten murni Larutan standar $\beta$ karoten diambil 1, 2, 3, 4, dan $5 \mathrm{~mL}$. Masing-masing tambahkan petroleum eter. Ukur absorbansi menggunakan Spektrofotometri $\mathrm{Uv}_{\mathrm{v}} \mathrm{Vis}$ panjang gelombang $450 \mathrm{~nm}$. Menurut (Amaya, dkk., 2004) panjang gelombang maksimum $\beta$-karoten adalah 450 .
Tabel 2. Hasil analisis kuantitatif menggunakan spektrofotometri UV-Vis

\begin{tabular}{clllc}
\hline & \multicolumn{4}{c}{ Kadar $\beta$-karoten } \\
\cline { 3 - 5 } No & Pisang raja & \multicolumn{3}{c}{ Pisang kepok } \\
\cline { 2 - 5 } & Abs & $\begin{array}{l}\text { Kadar } \\
(\mathrm{mg} / 100 \mathrm{~g})\end{array}$ & Abs & $\begin{array}{l}\text { Kadar } \\
(\mathrm{mg} / 100 \mathrm{~g})\end{array}$ \\
\hline 1. & 0,005 & 0,083 & 0,006 & 0,0997 \\
2. & 0,014 & 0,232 & 0,017 & 0,282 \\
3. & 0,021 & 0,350 & 0,024 & 0,400 \\
$\Sigma$ & & 0,664 & & 0,780 \\
$\overline{\boldsymbol{x}}$ & & 0,222 & & 0,261 \\
\hline
\end{tabular}

Perbedaan hasil dari kedua sampel disebabkan proses kematangan buah pisang menyebabkan penurunan dan kerusakan $\beta$-karoten. Faktor-faktor yang menyebabkan penurunan dan kerusakan $\beta$ karoten yaitu adanya oksigen, cahaya dan panas. $\beta$ karoten mudah teroksidasi ketika terkena udara. Hal ini disebabkaan karena adanya struktur ikatan rangkap pada molekul $\beta$-karoten. Oksidasi akan berlangsung lebih cepat dengan adanya cahaya, pemanasan dengan suhu tinggi.

Hasil analisis kadar $\beta$-karoten yang diperoleh dalam penelitian ini memiliki perbedaan dari berbagai sampel yang telah dilakukan penelitian sebelumnya dimana sampel daging buah pisang mengandung sedikit kadar $\beta$-karoten dibandingkan sampel lain seperti penelitaian sebelumnya tentang daging buah naga merah dan buah naga putih memiliki kadar $\beta$ karoten dari masing-masing yaitu $0,9995 \mathrm{mg} / 100 \mathrm{~g}$ dan $0,3628 \mathrm{mg} / 100$ g. Kadar $\beta$-karoten buah naga merah lebih tinggi dari buah naga putih, karena senyawa $\beta$-karoten merupakan pigmen yang berwarna kuning, orange, dan semakin merah warnanya maka semakin banyak $\beta$-karoten sedangkan pada daging buah pisang dapat diketahui semakin masak daging buah pisang maka semakin berkurang $\beta$-karotennya.

\section{Kesimpulan}

Simpulan dari penelitian ini adalah daging buah pisang raja dan daging buah pisang kepok mengandung $\beta$-karoten. Dilihat dari uji kualitatif yang dilakukan, yakni uji KLT dengan nilai Rf pembanding $0,97 \mathrm{~cm}$ dan untuk sampel daging buah pisang raja $0,96 \mathrm{~cm}$, daging buah pisang kepok 0,97 $\mathrm{cm}$.

Kadar $\beta$-karoten yang diperoleh dari daging buah pisang raja adalah $0,222 \mathrm{mg} / 100$ gram dan daging buah pisang kepok adalah 0,261 mg/100 gram. Kadar $\beta$-karoten daging buah pisang kepok lebih tinggi dari pada daging buah pisang raja.

\section{Ucapan Terima Kasih}

Ucapan terimakasih penulis sampaikan kepada Tasrik, laboran laboratorium Fakultas Keguruan dan Ilmu Pendidikan dan teman-teman yang telah memberikan bimbingan dan masukan dalam menyelesaikan penelitian ini. 


\section{Referensi}

Badarinath, A. V., Mallikarjuna, A., Chetty, C. M. S., Ramkanth, S., Rajan, T. V. S., \& Gnanaprakash, K. (2010). A review on in-vitro antioxidant methode comparisions, correlations and consideration. International. Jurnals. PharmTech Research, 2(2), 1276-1285.

Dwi, B. A. D., Zulharmita \& Wulan. (2015). Pemeriksaan kandungan $\beta$-karoten pada buah naga merah dan buah naga putih dengan metode spektrofotometri Uv-Vis. Universitas Sekolah Tinggi Ilmu Farmasi (STIFARM), 20(1), 146151.

Fitri, F., Roslinda, R., \& Reza, F. (2015). Pengaruh proses pengolahan terhadap kadar $\beta$-karoten pada ubi jalar varietas ungu (Ipomea batatas(l.) Lam) dengan metode spektrofotometri visible. Jurnal Farmasi Higea, 7(2), 152-161.

Hastinah. T. (1996). Kinetika degradasi ternal $\beta$ karoten dalam minyak sawit. Skripsi. Bogor: Institut Pertanian Bogor.

Mailoa, M. N., Mahendradatta, M., Laga, A., \& Djide, N. (2014). Effectiveness of tannins extract from leaf guava (Psidium guajava L) on the growth and damage of cell morphology escherichia coli. International Journal of Advanced Research, 2(1), 908-914.

Munadjim. (1988). Teknologi pengolahan pisang. Jakarta: PT Gramedia.

Parwata, I. M. O. A., Ratnayani, K., \& Listya, A. (2010). Aktivitas antiradikal bebas serta kadar beta karoten pada madu randu (ceiba pentandra) dan madu kelengkeng (Nephelium longata L.). Jurnal Kimia, 4(1), 54-62.
Prabawati, S., Suyanti, \& Setyabudi, D. A. (2008). Teknologi teknologi pascapanen dan pengolahan buah pisang. Bogor: Balai Besar Penelitian dan Pengembangan Pascapanen Pertanian.

Priata, A. (1996). Produk non-volatil dari degradasi ternal $\beta$-karoten didalam medium minyak. Skripsi Bogor: Institut Pertanian Bogor.

Sarjana, I. M. (1997). Pemanfaatan limbah kulit buah pisang sebagai bahan baku pembuatan etanol. Skripsi. Palu: Universitas Tadulako.

Sholihati, Abdullah, R. \& Suroso. (2015). Kajian penundaan kematangan pisang raja raja (musa paradisiaca var sapientum 1.) melalui penggunaan media penyerapan etilen kalium permanganat. Jurnal Rona Teknik Pertanian 8(2), 1-14.

Tadjuddin, N., Andi, M., \& Mas, M. O. I. (2012). Analisis kadar ß-karoten pada buah pare (momordica charantia 1.) asal ternate secara spektrofotometri UV-Vis. Majalah Farmasi dan Farmakologi, 16(3), 127-130.

Triyati, E. (1985). Spektrofotometer ultra violet dan sinar tampak serta aplikasinya dalam oseanologi. Oseana, 10(1), 39-47.

Utami, S., Wwidiyanto, J., \& Kristianita. (1999). Pengaruh cara dan lama pemeraman terhadap kandungan vitamin c pada buah pisang raja (Musa paradisiaca L.). Edukasi Matematika dan Sains, 2(1), 42-46.

Wari, P., Kumar, B., Kaur, M., Kaur, G., \& Kaur, H. (2011). Phytochemical screening and extraction: A review. Internationale Pharmaceutica Sciencia, 1(1), 98-106. 